\title{
Arquitetura Eficiente
}

\section{Efficient Architecture}

Prof. Dr. Leandro Medrano

Faculdade de Engenharia Civil, Arquitetura e Urbanismo da Unicamp Contato: Medrano@fec.unicamp.br

Os modelos urbanos e
arquitetônicos vigentes nas cidades
contemporâneas demonstram, há
tempos, sinais de obsolescência. Instrumentos que no passado permitiram desenvolvimento econômico, cultural e social à urbe e à metrópole não suportaram a pressão dos padrões de governança laissez faire, ditados ao extremo desde as últimas décadas do século XX. Em um mundo cuja população é majoritariamente urbana, a busca por formas de habitabilidade que garantam qualidade de vida e crescimento sustentável tornou-se uma das principais preocupações das agendas políticas de seus dirigentes. Cidades como Paris, Barcelona, Madri, Londres, Tókio, Hong Kong, Nova Iorque, Chicago e São Paulo expressam, em sítios oficiais na Internet, o desejo de organizar estratégias que viabilizem melhores perspectivas para as próximas décadasi. Essas novas plataformas virtuais informam e discutem os desejos e idéias de especialistas, gestores e cidadãos em relação ao futuro de suas cidades. Dentre os temas tratados, destacam-se o sistema de transporte, a economia, o meio ambiente, a segurança, a educação, a saúde, a qualidade de vida, o desenvolvimento econômico, a cultura etc. Entretanto, em praticamente todos os exemplos disponíveis nessa espécie de ágora eletrônica, ainda são poucas as realizações condizentes com as prementes demandas designadas ao campo da arquitetura e do urbanismo. As cidades buscam eficiência.

Em relação à arquitetura, e ao setor da construção civil como um todo, a procura por soluções "sustentáveis" está presente tanto no mercado quanto na academia há algumas décadas, e são muitas as soluções e propostas publicadas em diversos meios de divulgação, especializados ou não. Algumas conquistas são evidentes, como a otimização do uso da água, os materiais recicláveis, os sistemas de isolamento (nos países de clima frio), a criação de instrumentos de controle (como o selo Procel) etc. Entretanto, considerando o alto impacto do setor ao meio ambiente, que chega a consumir entre $40 \%$ e $75 \%$ dos recursos extraídos da natureza, ainda estamos longe do ideal ou desejável. Como exemplo, temos a Espanha e EUA (dentre outros países desenvolvidos), que tiveram suas economias recentemente movimentadas pelo crescimento em áreas ligadas à construção civil. Em ambos os casos, constatou-se que, apesar dos avanços tecnológicos e teóricos em questões relacionadas ao desenvolvimento sustentável, a maior parte dos empreendimentos construídos no boom imobiliário que antecedeu a crise de 2008 utilizou procedimentos tradicionais e pouco eficientes em relação ao meio ambiente. Nos EUA, por exemplo, o modelo da "sprawl city", amplamente criticado no meio acadêmico (e.g. os conceitos de "Compact City" e "Smart Growth"), prevalece ainda em subúrbios intermináveis de habitações unifamiliares convencionais, que subaproveitam a infra-estrutura urbana e dependem do transporte individual por automóvel. A Espanha, cujos arquitetos e pesquisadores desenvolvem com assiduidade soluções inovadoras para esse problema, teve a maior parte da sua recente expansão no mercado de imóveis conduzida por técnicas tradicionais de construção - de grande impacto ao meio ambiente. Essa opção é justificada pelos governantes e empreendedores por permitir o aumento na oferta de 
empregos a trabalhadores pouco qualificados e, dessa forma, ampliar a abrangência dos benefícios econômicos resultantes.

No campo do urbanismo, a situação não parece ser diferente. Apesar dos diversos estudos orientados a modelos mais eficientes e sustentáveis de urbanização (e.g. JENKS, 2001; NEUMAN, 2005), são poucas as cidades que realmente adotaram uma agenda comprometida com novas e melhores formas de crescimento. Soluções paliativas e de grande visibilidade em termos de marketing governamental, como o transporte por bicicletas, parecem encobrir a falta de gerência e planejamento em temas de grande impacto ao meio ambiente, como o sistema de transporte, a utilização dos recursos hídricos, a coleta e tratamento do lixo, o mercado imobiliário etc. As relações de interdependência econômica e política sedimentadas entre esses setores e as esferas de governança, crescente no avanço dos modelos neoliberais de gestão (JUDT, 2011), não permitiram ações efetivas em relação às agressivas estratégias de desenvolvimento ditadas pelos interesses de empreendedores privados. São exemplos disso os grandes edifícios ou condomínios verticais isolados da malha urbana, os sistemas viários desenhados para o transporte individual por automóvel, o crescimento desnecessário e pouco planejado da mancha urbana, a transformação de reservas naturais em áreas urbanizáveis, os grandes "monumentos" arquitetônicos sem finalidade etc., exemplos comuns em países desenvolvidos, emergentes e pobres (e.g. projeto do MVRDV para Tirana, figuras 1 , 2 e 3$)$.
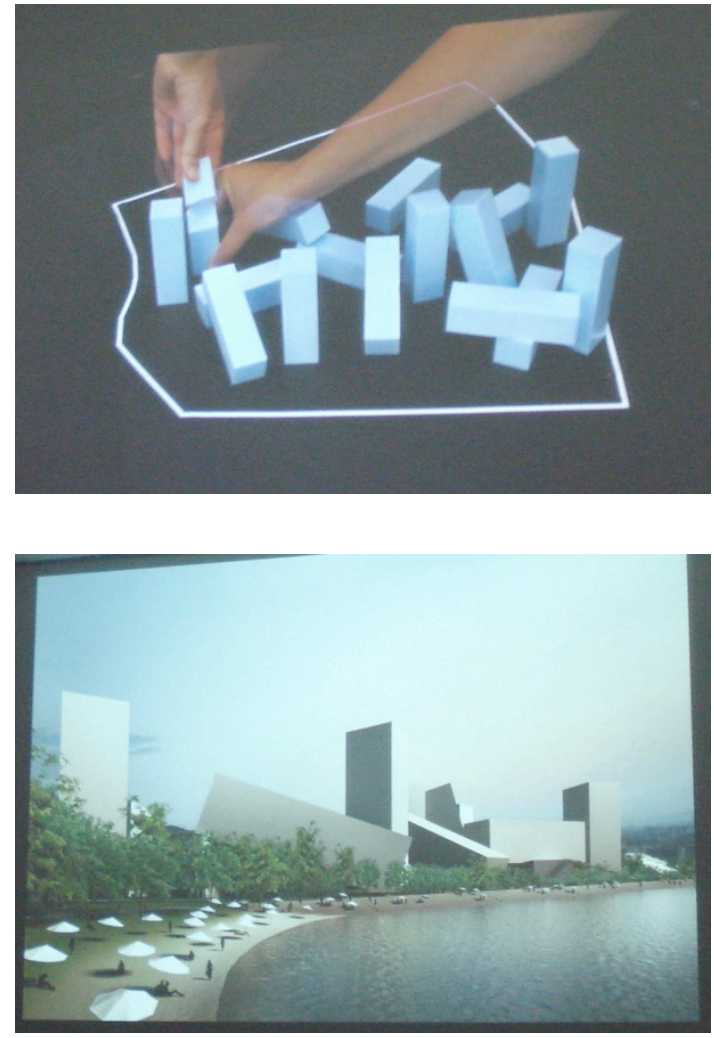

Figuras 1, 2 e 3: projeto do escritório MVRDV para área de edifícios verticais em um parque urbano da cidade de Tirana, na Albânia. Apresentado em outubro de 2012 na TAW cientific conference. Fotos do autor.

No Brasil, a primeira década do século XXI foi orientada por significativas mudanças. A estabilidade econômica, os avanços do setor produtivo e as políticas públicas de inclusão social, em conjunto com a consolidação da democracia, permitiram ao país crescimento e otimismo em ritmo singular na sua história. A perspectiva de sediar a Copa do Mundo de Futebol, em 2014, e as Olimpíadas, em 2016, e o lançamento do Programa Minha Casa Minha Vida (que ambiciona construir, até 2014, 2 milhões de habitações para a população de baixa renda), estimulam os ânimos desenvolvimentistas - principalmente no setor da construção civil. Entretanto, por enquanto, não há evidências de que esse crescimento resulte em cidades mais eficientes, sustentáveis e com boa qualidade de vida. Demais, as políticas recentes de estímulo à compra de automóveis, a precariedade do 
transporte público e a falta de urbanidade das unidades já construídas pelo PMCMV demonstram um caminho inverso aos ideais de planejamento consagrados em bem sucedidas experiências atuais e do passado ${ }^{\text {ii }}$.

Um exemplo de cidade brasileira que se desenvolve em ritmo e forma insustentável é a megacidade São Paulo. Com mais de 19 milhões de habitantes em sua região metropolitana, ostenta dados impressionantes: aproximadamente $120 \mathrm{~km}$ de congestionamentos em seus horários críticos; velocidade média dos automóveis de $15 \mathrm{~km} / \mathrm{h}$ (das $17 \mathrm{~h}$ às 20h); alto índice de violência urbana; 1538 favelas (que abrigam 11\% da população); $\quad 400.000 \quad$ edifícios desocupados (grande parte na região central); transporte público precário etc. São Paulo é uma cidade eficiente?

A maior e mais rica cidade da América do Sul parece ir na contra-mão das expectativas desejadas para seu futuro. Após alguns avanços em setores estratégicos, como a reurbanização da área central coligada a políticas públicas de inclusão social (NOBRE, 2009) e alguns avanços no sistema público de transportes, com a criação de novos corredores de ônibus e do "bilhete único" iii, a cidade vivenciou anos de expansão e desenvolvimento em ritmo acelerado e praticamente sem planejamento. Como conseqüência, surgem bairros desfigurados por um agressivo processo de verticalização e adensamento - alijados de qualquer modelo de desenho urbano -, cujas transformações prejudicam o trânsito, o meio ambiente e a qualidade urbana em geral. Uma cidade à beira do caos cujo prefeito finaliza seu mandato, em 2012, com um dos piores níveis de aprovação já registrados em sua história recente ${ }^{\text {iv }}$.

Assim, o "caos sistêmico", geralmente predominante nas periferias e favelas de São Paulo, nos últimos anos, encontrou também seu lugar nos bairros nobres da cidade. Com o crescimento do mercado imobiliário e os instrumentos do novo Plano Diretor Estratégico do Município de São Paulo, aprovado em setembro de 2002, bairros tradicionais, como a Vila Madalena e Pinheiros, transformaram-se da noite para o dia. $\mathrm{O}$ ritmo das demolições de casas e edifícios de poucos pavimentos, para dar lugar a grandes edifícios verticais, assusta urbanistas e morados que questionam a ausência de infra-estrutura adequada a esse abrupto processo de adensamento sem planejamento ${ }^{\text {vi }}$. É certo que o aumento da densidade habitacional poderia ser uma estratégia adequada a esses bairros, com vistas aos benefícios de uma cidade mais compacta, diversificada e interconectada. Entretanto, sem os estudos e investimentos condizentes com esse modelo de urbanização, a expectativa é que os muitos problemas existentes sejam intensificados.

No setor das habitações de interesse social, concursos e fóruns de discussão fomentaram novos ideais para o setor, como o "Renova São Paulo" e o "São Paulo Calling". Entretanto, a abrangência dessas iniciativas teve pouca influência nas necessidades dos quase dois milhões de habitantes da cidade que vivem em assentamentos precários. Outrossim, algumas das poucas obras construídas nessas áreas, como o projeto do arquiteto Ruy Ohtake para a favela de Heliópolis, revelam a falta de atualização teórica, conceitual e metodológica que parte dos profissionais do setor transmite - sob um verniz de boas intenções - por meio de suas propostas para a cidade $\mathrm{e}^{\mathrm{vii}}$.

Em descompasso com as agressivas práticas de crescimento presenciadas, nas últimas décadas, por cidades de todo o mundo, os avanços no campo das técnicas, formas de gestão e planejamento sustentáveis, estimulam pesquisas relacionadas à área - tanto na academia quanto no mercado. As 
"certificações" (LEED, AQUA, HQE, AzulCAIXA etc.), os "selos de controle" (para materiais e produtos sustentáveis), os instrumentos de auxílio ao projeto (como softwares de aferição ou simulação) e a qualificação dos processos e mecanismos de gerenciamento (da construção e da cidade), revelam a evolução dos procedimentos "ecologicamente corretos” em diversas áreas da ciência. Entretanto, como vimos em alguns exemplos indicados neste editorial, ainda é grande a distância entre os avanços teóricos ou tecnológicos desenvolvidos nos centros de pesquisas, e as práticas usuais de planejamento, gestão e construção das cidades contemporâneas.

Nesse contexto, o papel do arquiteto se constringe, pois não há arquitetura eficiente em cidades sem eficiência.

\section{Referências bibliográficas}

JENKS, M. Compact Cities: Sustainable Urban Forms for Developing Countries. [S.l.] Taylor \& Francis, 2001.

JUDT, T. Ill Fares the Land. 1. ed. [S.l.] Penguin Books, 2011.

Moradores se unem contra verticalização saopaulo - Estadao.com.br. Disponível em: <http://www.estadao.com.br/noticias/impres so,moradores-se-unem-contra-verticalizacao,875275,0.htm>. Acesso em: 27 out. 2012.

NEUMAN, M. The Compact City Fallacy. Journal of Planning Education and Research, v. 25, n. 1, p. 11-26, 1 set. 2005.

NOBRE, E. Políticas urbanas para o centro de São Paulo: renovação ou reabilitação? Avaliação das propostas da prefeitura do município de São Paulo de 1970 a 2004. Pós. Rev Programa Pós-Grad Arquit Urban. FAUUSP, v. 25, p. 214-231, 2009.
ROLNIK, R.; KLINTOWITZ, D. (I)Mobilidade na cidade de São Paulo. Estudos Avançados, v. 25, n. 71, p. 89-108, abr. 2011.

SMITH, N. Después del neoliberalismo: ciudades y caos sistémico. [S.l.] Univ. Autònoma de Barcelona, 2009.

ZARATTINI, C. Circular (ou não) em São Paulo. Estudos Avançados, v. 17, n. 48, p. 185-201, ago. 2003.

\section{Notas}

\footnotetext{
E.g. alguns endereços que divulgam e discutem o planejamento, a médio e longo prazo, das cidades:

Chicago Go To 2040; Hong Kong 2030; The London Plan; PlanNYC 2030; Tokyo's Big Chance; Barcelona $\underline{2020}$.
}

ii As realizações, no início do século XX, de Bruno Taut
e Ernest May, o bairro Tiburtino, construído em Roma
após a Segunda Guerra, bem como os recentes bairros
de ljburg (Amsterdam), NordHavnen e Orestad
(Copenhague) o Plano 22@ (Barcelona), os P.A.U.s de
Madri, dentre outros, são exemplos de estratégias
planejadas de atualização urbana e crescimento. Tais
realizações, com finalidades diversas, não possuem
avaliação consensual da critica especializa ou da
população, entretanto, foram argumentadas,
planejadas e desenhadas em acordo com os
procedimentos democráticos desejados à
transformações urbanas de médio ou grande porte.

iii Conforme pesquisas recentes na área, o modelo de transporte baseado no automóvel ainda prevalece nos investimentos do município de São Paulo, e os investimentos em transporte público estão aquém das urgentes necessidades da cidade (ROLNIK; KLINTOWITZ, 2011; ZARATTINI, 2003) 
iv Como demonstra pesquisa do instituto Vox Populi publicada no dia 24/09/2012.

$\checkmark$ Em 2008, o MACBA realiza um seminário intitulado "Después Del Neoliberalismo: ciudades y caos sistêmico", que daria origem, no ano seguinte, à uma publicação com o mesmo nome. A intenção foi ampliar as discussões relacionadas aos impactos das políticas neoliberais no desenvolvimento urbano de cidade de todo o mundo (SMITH, 2009)

vi Sobre o tema, recentemente, diversas reportagens foram publicadas. A maior indignação de especialistas e moradores é não é por conta da verticalização ou adensamento, mas sim pela ausência de planejamento ou estudos sobre as condições desse processo. E.g. ("Moradores se unem contra verticalização saopaulo - Estadao.com.br", [S.d.])

vii A proposta, amplamente divulgada, pode ser vista na revista eletrônica Arcoweb (http://www.arcoweb.com.br/arquitetura/ruy-ohtakecentro-educativo-cultural-condominio-residencialheliopolis-04-04-2012.html). 